\title{
Stable Isotope Values in South American Fur Seal Pup Whiskers as Proxies of Year-round Maternal Foraging Ecology
}

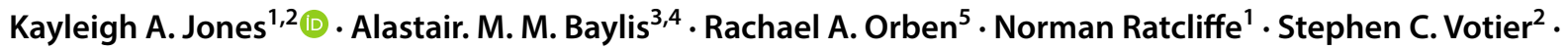 \\ Jason Newton ${ }^{6} \cdot$ lain J. Staniland ${ }^{1}$
}

Received: 9 April 2020 / Accepted: 28 August 2020 / Published online: 29 September 2020

(c) The Author(s) 2020

\begin{abstract}
Natural selection should favour strategies that maximise reproductive success. Females may use different resources during progressive stages of reproduction according to energetic demands, behavioural constraints and prey availability. We used South American fur seal, Arctocephalus australis australis, pup whisker isotope values as proxies for maternal diet and habitat use to determine how resource use (1) changes throughout pup development from in utero growth to mid-end of lactation and (2) how it differs among individuals. The longest whisker was cut from 5 male and 5 female fur seal pups (of approximately 8 months of age) at Bird Island, Falkland Islands, in 2018, and $\delta^{15} \mathrm{~N}$ values and $\delta^{13} \mathrm{C}$ values were analysed every $5 \mathrm{~mm}$ along the length of each whisker. Patterns in $\delta^{13} \mathrm{C}$ values indicated that mothers used different habitats during the annual cycle, likely coinciding with seasonal shifts in prey availability or distribution. The individual specialisation index based on $\delta^{13} \mathrm{C}$ values was 0.34 , indicating that adult females used different habitats, which could reduce intra-specific competition and ultimately enhance pup growth and survival. An increase in $\delta^{15} \mathrm{~N}$ values occurred along every pup whisker from pup birth to mid-end of lactation, which likely reflected trophic enrichment related to suckling and fasting by pups, overriding the maternal isotopic signature. Pup whisker stable isotopes are useful proxies of maternal foraging ecology. However, physiological processes complicate interpretations by altering $\delta^{15} \mathrm{~N}$ values. Interpreting these values therefore requires additional knowledge of the species' ecology and physiology.
\end{abstract}

\section{Introduction}

Responsible Editor: C. Harrod.

Reviewed by undisclosed experts.

Kayleigh A. Jones

kayleighannjones211@gmail.com

1 British Antarctic Survey, High Cross, Madingley Rd, Cambridge CB3 0ET, UK

2 University of Exeter, Penryn Campus, Penryn, Cornwall TR10 9FE, UK

3 South Atlantic Environmental Research Institute, Stanley Cottage, PO Box 609, Stanley FIQQ 1ZZ, Falkland Islands

4 Department of Biological Sciences, Macquarie University, Sydney, NSW 2109, Australia

5 Department of Fisheries and Wildlife, Oregon State University, Hatfield Marine Science Center, 2030 SE Marine Science Dr, Newport, OR 97365, USA

6 National Environmental Isotope Facility, Scottish Universities Environmental Research Centre, Rankine Avenue, East Kilbride G75 0QF, UK
In mammals, gestation and lactation have different energetic requirements that influence maternal resource use (Gittleman and Thompson 1988). During gestation, female mammals must grow and maintain foetal, uterine, placental and mammary tissues, which is particularly demanding towards the end of gestation when the foetus is large (Gittleman and Thompson 1988; Hückstädt et al. 2018). During lactation, maternal metabolism dramatically increases as nutrients are transferred to the mammary glands to produce milk for offspring (Crocker et al. 1998). Some otariid (eared seal) species are concurrently pregnant while lactating, so have higher costs of breeding than otariids that do not lactate and gestate simultaneously (Lima and Páez 1995). Otariids are also central place foragers and must alternate between foraging at sea and suckling pups ashore. Hence, the distance and duration of successful foraging trips are limited by the fasting ability of offspring (Villegas-Amtmann et al. 2017). As a result of these changing demands, females may alter their 
diet and habitat use during offspring development (Krebs and Davies 1997; Berger 1991; Rachlow and Bowyer 1998).

Changes in maternal foraging ecology during gestation and lactation could also differ among individual mothers (Rea et al. 2015). This is because body size, age and experience can affect diet preference, search efficiency and prey handling ability (Estes et al. 2003; Villegas-Amtmann et al. 2008; Jeglinski et al. 2012; Baylis et al. 2016). Individuals may therefore consistently use only a subset of resources available to all individuals within the population (Zango et al. 2019). Individual specialisation by mothers can reduce competitive interactions within a population and so enhance offspring growth, survival and ultimately maternal fitness (Laidre et al. 2008; Bowman et al. 2010; Urquía and PáezRosas 2019). During lactation, individual offspring may also allocate the energy they obtain from ingesting milk differently into their own development, as a result of their sex, condition and body size (e.g. McDonald et al. 2012a, b). For example, female Antarctic fur seal pups, Arctocephalus gazella, and Australian fur seal pups, Arctocephalus pusillus doriferus, may allocate more energy into accumulating fat stores whereas males allocate more energy into growing lean body tissues (Arnould et al. 1996; Arnould and Hindell 2002). Hence, quantifying individual specialisation and accounting for how offspring allocate energy enables a more complete understanding of maternal resource use.

Offspring are usually easier to capture and handle than adults and stable isotopes in young animals have been used as proxies for maternal foraging behaviour in sharks (Olin et al. 2011), cetaceans (Meissner et al. 2012) and pinnipeds (Wolf et al. 2008; Drago et al. 2010; Lowther and Goldsworthy 2011; Hindell et al. 2012). Stable isotopes reflect the ratio of heavy to light isotopes used by an organism, plus an added trophic discrimination factor from processes involved in assimilating into growing tissues (Ben-David and Flaherty 2012). Nitrogen isotope ratios $\left({ }^{15} \mathrm{~N} /{ }^{14} \mathrm{~N}\right.$ expressed as $\left.\delta^{15} \mathrm{~N}\right)$ generally indicate trophic position, as they increase with trophic level since ${ }^{15} \mathrm{~N}$ is preferentially retained in the body and ${ }^{14} \mathrm{~N}$ excreted in urine and faeces (Minagawa and Wada 1984; Fry 1988; DeNiro and Epstein 1976; Post 2002). In marine systems, carbon isotope ratios $\left({ }^{13} \mathrm{C} /{ }^{12} \mathrm{C}\right.$ expressed as $\delta^{13} \mathrm{C}$ ) indicate geographic source of prey, as $\delta^{13} \mathrm{C}$ values in primary producers generally decline with increasing latitude and are typically higher in benthic and inshore regions than pelagic and offshore regions (Hobson et al. 1994; France 1995; Kelly 2000; McCutchan et al. 2003).

In addition to considering ecological processes, interpreting isotope values relies on an understanding of the influence of physiological processes, such as growth, pregnancy and nutritional stress (McHuron et al. 2019). Foetal development likely requires a constant and reliable supply of energy, in which remobilised endogenous maternal proteins are primarily used for foetal protein synthesis, as revealed by amino acid analyses along southern elephant seal, Mirounga leonina, pup whiskers (Lübcker et al. 2020). Indeed, this mechanism can cause a gradual enrichment in $\delta^{13} \mathrm{C}$ along pup whiskers during gestation (Lübcker et al. 2020). Furthermore, trophic level enrichment in ${ }^{15} \mathrm{~N}$ often occurs from mother to offspring during lactation in mammals (Jenkins et al. 2001; Aurioles et al. 2006). Fasting also leads to increased $\delta^{15} \mathrm{~N}$ values in tissues of several marine species, including northern elephant seals, Mirounga angustirostris (Spurlin et al. 2019), king penguins, Aptenodytes patagonicus (Cherel et al. 2005) and polar bears, Ursus maritimus (Polischuk et al. 2001). Since ecological and physiological processes vary among species, isotope profiles in offspring are species and tissue specific (Jenkins et al. 2001).

Whiskers from South American fur seal pups, Arctocephalus australis australis, provide an ideal case study of maternal resource use during an extended period of pup development. Pup whiskers are composed of keratin, they are inert (in terms of isotope ratios) at formation, continuously grow and reach over $8 \mathrm{~cm}$ in length towards the end of lactation. Stable isotopes can therefore be analysed over a fine temporal scale throughout offspring development, from in utero growth to lactation, by sampling segments along the length of pup whiskers. Adult female South American fur seals give birth on pupping beaches around mid-December (Franco-Trecu 2005), then alternate between suckling their pups on land, and foraging at sea over a period of $\sim 10$ months. Beginning in March-April, adult females must provide energy to their nursing pup as well as their growing foetus (Lima and Páez 1995). They are effectively central-place foragers year-round, only free from breeding constraints for about 2 months between weaning their pup in October and giving birth in December. Changes in $\delta^{13} \mathrm{C}$ values along whiskers therefore more likely reflect inshore/ benthic foraging vs offshore/pelagic foraging, as opposed to foraging over a large latitudinal gradient (e.g. Cherel et al. 2009). Mothers may take longer foraging trips towards the end of lactation, as they have higher energetic demands of supporting a large pup and developing foetus, and their pups can withstand longer fasts for up to several weeks (Thompson et al. 2003; Baylis et al. 2018a). Since fur seals target oceanographic features that enhance biological productivity and aggregate prey (Baylis et al. 2008), they may also feed on different prey according to seasonal changes in oceanography and prey availability (Laptikhovsky 2009). Trends in $\delta^{15} \mathrm{~N}$ values along whiskers can reflect these dietary changes, but physiological processes (i.e. pregnancy, lactation and fasting) should also be accounted for.

Studying maternal foraging ecology in South American fur seals is valuable, given marine megafauna are often regarded as playing important roles in ecosystem structure and function (Estes et al. 2016), and compared to other otariid species, South American fur seals are poorly studied. 
Indeed, in the Falklands, which hosts the largest population in the world, research has been limited to only a handful of studies (Thompson et al. 2003; Laptikhovsky 2009; Baylis et al. 2014, 2018a, b, 2019). We aimed to determine how stable isotope values of South American fur seal pup whiskers from the Falklands change throughout pup development from in utero growth to mid-end of lactation and how these differ among individuals. We interpret trends in $\delta^{13} \mathrm{C}$ and $\delta^{15} \mathrm{~N}$ values by considering habitat use, diet and physiological processes.

\section{Materials and methods}

\section{Ethics statement}

The procedures in this study were reviewed and approved by the Falkland Islands Government (permit R19/2018). Every effort was made to minimise disturbance, and no pups were injured during handling procedures.

\section{Sample collection and preparation}

Fieldwork was conducted at Bird Island, Falkland Islands $\left(52.1678^{\circ} \mathrm{S}, 60.9260^{\circ} \mathrm{W}\right)$, from 12 th -18 th August 2018. Only 10 pups were sampled as a result of funding and time constraints. Five male and 5 female pups of approximately 8 months of age (assuming peak births occurred in midDecember; Franco-Trecu 2005) were selected at the edge of the colony to reduce disturbance. Each pup was caught in a net and measured (total body length, girth, fore flipper length, fore flipper width, fore flipper end, i.e. length between the first and fifth digits, hind flipper length and ankle), and the longest whisker was cut from the right side of the face as close to the skin as possible. Since pups were caught away from breeding females, body measurements were considered more reliable indicators of pup size than mass, as mass fluctuates substantially according to milk consumption (e.g. Jones et al. 2020a).

Whiskers were cleaned with a sponge and Ecover washing-up liquid, placed in an ultrasonic water bath for 5 minutes, inspected under a microscope (any dirt was removed with a scalpel blade), then rinsed with $100 \%$ ethanol. Sample segments weighing a target mass of $0.7 \mathrm{mg}$ (which weighed $0.66 \mathrm{mg}$ on average) were cut every $5 \mathrm{~mm}$ along the length of each whisker (from base to tip), then weighed into $3 \times 5 \mathrm{~mm}$ tin capsules. Samples $(n=173)$ were loaded into an Elementar (Hanau, Germany) Pyrocube Elemental Analyser (Scottish Universities Environmental Research Centre, UK), which converted carbon and nitrogen in the samples to $\mathrm{CO}_{2}$ and $\mathrm{N}_{2}$ gases. Stable isotope ratios $\left(\delta^{13} \mathrm{C}\right.$ and $\left.\delta^{15} \mathrm{~N}\right)$ of evolved gases were measured on a Thermo-Fisher-Scientific (Bremen, Germany)
Delta XP Plus Isotope Ratio Mass Spectrometer (IRMS). Ratios were corrected for instrument drift and linearity using interspersed samples of reference materials with known stable isotope values (mean $\pm \mathrm{SD}$ ): GEL (gelatin solution, $\delta^{13} \mathrm{C}=-20.09 \pm 0.19 \%$ o, $\delta^{15} \mathrm{~N}=5.59 \pm 0.12 \%$ ) ALAGEL (alanine-gelatine solution spiked with ${ }^{13} \mathrm{C}$-alanine, $\delta^{13} \mathrm{C}=-8.69 \pm 0.17, \delta^{15} \mathrm{~N}=2.22 \pm 0.08 \%$ ) and GLYGEL (glycine-gelatine solution spiked with ${ }^{15} \mathrm{~N}$-alanine, $\delta^{13} \mathrm{C}=-38.35 \pm 0.13 \% o, \delta^{15} \mathrm{~N}=23.19 \pm 0.22 \%$ ) , each dried for $2 \mathrm{~h}$ at $70{ }^{\circ} \mathrm{C}$. Four USGS 40 glutamic acid standards (Qi et al. 2003; Coplen et al. 2006) were also used as independent checks of accuracy. Stable isotope ratios were expressed in parts per thousand (\%o) deviation from the international standards (Vienna Pee Dee Belemnite for carbon and AIR, $\mathrm{N}_{2}$ for nitrogen) according to the following equation:

$\delta X=\left[\left(R_{\text {sample }} / R_{\text {standard }}\right)-1\right]$,

where $X$ is ${ }^{15} \mathrm{~N}$ or ${ }^{13} \mathrm{C}$ and $R$ is the corresponding ratio $\left({ }^{15} \mathrm{~N} /{ }^{14} \mathrm{~N}\right)$ or $\left({ }^{13} \mathrm{C} /{ }^{12} \mathrm{C}\right)$.

\section{Data analysis}

All data analyses were conducted in $\mathrm{R}$ version 3.6.0. (R Core Team 2019). To indicate whether male pups invested more energy into whisker growth than female pups, as found in adults of closely related otariid species (e.g. Kernaléguen et al. 2015; Jones et al. 2020b), we conducted a Welch's $t$-test on whisker lengths (as data were normally distributed and had unequal variances). We also tested whether body morphology significantly differed between 4 male pups (as girth was not obtained for male P7 and we considered girth an important indicator of body size) and five female pups by running a Principal Components Analysis (PCA) on body measurements and testing the output from Principal Component 1 (PC1) and Principal Component 2 (PC2) in Welch's $t$-tests.

For each pup whisker, the convex hull area was calculated as a measure of isotopic niche width using the SIBER package (Jackson et al. 2011). Locally weighted scatterplot smoothers (LOESS) were then fitted to $\delta^{15} \mathrm{~N}$ values along the length of each whisker, revealing distinct troughs in values where the minimum $\delta^{15} \mathrm{~N}$ value presumably occurred close to timing of pup birth, as reported in whiskers of Steller sea lion, Eumetopias jubatus, pups (Rea et al. 2015). This trough was used to estimate growth rate of each whisker (per month) by dividing whisker length from the facial end to the minimum $\delta^{15} \mathrm{~N}$ value by pup age at capture ( $\sim 8$ months). Whisker growth rates were then used to estimate pup age at every $5 \mathrm{~mm}$ interval along the length of each whisker (including in utero).

To determine how stable isotope values changed on a continuous scale throughout pup development, $\delta^{13} \mathrm{C}$ and $\delta^{15} \mathrm{~N}$ 
values were used as separate response variables in generalised additive mixed models (GAMMs) using the mgcv package in $\mathrm{R}$ (Wood 2017). Predictor variables in candidate models included pup age, sex and their interactions. Pup ID was specified as a random intercept and smooth effect to account for variability in $\delta^{13} \mathrm{C}$ and $\delta^{15} \mathrm{~N}$ values among individuals, and a corARMA structure $(p=2, q=0)$ was applied to account for temporal autocorrelation in residuals. Models were ranked by Akaike Information Criterion (AIC) and the best-fit model for each analysis was selected according to the lowest AIC (the simplest model was selected if models differed by less than 2 AIC units). Residual plots were checked for normality and homoscedasticity. To give a broad indication of how pup isotope values compared with those of adult females, mean $\delta^{13} \mathrm{C}$ and $\delta^{15} \mathrm{~N}$ values in whiskers of 14 adult females (Baylis et al. unpublished data) in segments that were grown approximately over the same time period as pup whiskers were included in figures (these females were not the pups' mothers).

Individual specialisation indices in pup $\delta^{13} \mathrm{C}$ and $\delta^{15} \mathrm{~N}$ values were also quantified to determine the average similarity among individuals and the sample population (Araújo et al. 2011). The variance components were partitioned from each best-fit model and the within individual component (WIC) was divided by the total niche width (TNW, i.e. the sum of the variance components). An individual specialisation value of zero indicates individuals are complete specialists, whereas a value of one indicates individuals occupied the whole range of the sample population's (isotopic) niche (Roughgarden 1972; Bolnick et al. 2002).

To broadly determine whether isotope values differed between the sexes and among different stages of pup growth, as well as quantify variance in isotopes values among these stages, $\delta^{13} \mathrm{C}$ and $\delta^{15} \mathrm{~N}$ values were used as separate response variables in linear mixed effects models using the nlme package (Pinheiro et al. 2019). Predictor variables in candidate models included stage of pup growth based on the known life cycle (pup growing in utero while mother suckles an older pup; pup growing in utero while mother is free from nursing constraints; pup suckling from the mother), sex, and their interactions. Pup ID was also specified as a random intercept to account for variability in $\delta^{13} \mathrm{C}$ and $\delta^{15} \mathrm{~N}$ values among individuals. Levene's tests were conducted to determine whether variance in $\delta^{13} \mathrm{C}$ and $\delta^{15} \mathrm{~N}$ values differed among stages of pup growth. To indicate the statistical power of the linear mixed effects models, repeatability indices of $\delta^{13} \mathrm{C}$ and $\delta^{15} \mathrm{~N}$ values were estimated (while accounting for individual and stage of pup growth) using the R package rptR (Stofell et al. 2019). Repeatability indices show the proportion of variation that is reproducible by comparing the original data with simulated response data from the fitted model using parametric bootstrapping (Nakagawa and Schielzeth 2010). All results were reported as means \pm standard deviation unless otherwise stated.

\section{Results}

\section{Pup morphology}

Pup whisker length averaged $9.28 \pm 0.38 \mathrm{~cm}$ and did not significantly differ between the sexes (Welch's $t$-test: $t=0.35, P=0.74$; Table 1). Pup whisker growth rates averaged $0.67 \pm 0.14 \mathrm{~cm}$ per month and also did not differ significantly between the sexes (Welch's $t$-test: $t=1.33$, $P=0.84$; Table 1). Males were slightly larger in body size than females, as indicated by PCA. Specifically, loadings for PC1 were highest for fore flipper end (0.44), followed by fore flipper width (0.42), hind flipper length $(0.40)$, body length (0.36), ankle (0.36), fore flipper length $(0.33)$ and girth (0.30), while loadings for PC2 were highest for girth $(0.62)$, followed by fore flipper length $(-0.59)$, body

Table 1 Range in $\delta^{13} \mathrm{C}$ and $\delta^{15} \mathrm{~N}$ values and convex hull area for each South American fur seal pup whisker

\begin{tabular}{llllllll}
\hline Pup ID & Sex & $\begin{array}{l}\text { Body length } \\
(\mathrm{cm})\end{array}$ & $\begin{array}{l}\text { Whisker } \\
\text { length }(\mathrm{cm})\end{array}$ & $\begin{array}{l}\text { Whisker } \\
\text { growth rate } \\
(\mathrm{cm} / \mathrm{month})\end{array}$ & $\begin{array}{l}\delta^{13} \mathrm{C} \text { range } \\
(\%)\end{array}$ & $\begin{array}{l}\delta^{15} \mathrm{~N} \text { range }(\%) \\
\text { Convex hull }\end{array}$ \\
\hline P1 & F & 78 & 8.7 & 0.75 & -16.15 to -14.43 & $15.57-17.21$ & 2.02 \\
P2 & F & 81 & 10 & 0.75 & -16.76 to -14.85 & $13.52-16.52$ & 1.11 \\
P8 & F & 95 & 10 & 0.81 & -16.08 to -14.19 & $15.38-17.75$ & 2.34 \\
P9 & F & 78 & 7.5 & 0.56 & -17.11 to -15.13 & $13.90-17.13$ & 3.57 \\
P10 & F & 88 & 9.5 & 0.69 & -15.81 to -14.15 & $15.25-18.53$ & 2.86 \\
P3 & M & 93 & 10 & 0.81 & -16.46 to -14.75 & $14.92-17.68$ & 2.95 \\
P4 & M & 87 & 7.1 & 0.38 & -15.71 to -14.56 & $15.64-17.04$ & 0.95 \\
P5 & M & 95 & 10.5 & 0.56 & -15.87 to -14.89 & $15.37-17.06$ & 0.69 \\
P6 & M & 83 & 10.5 & 0.56 & -16.29 to -15.09 & $15.11-17.42$ & 1.87 \\
P7 & M & 84 & 9 & 0.69 & -16.73 to -14.62 & $15.06-17.77$ & 2.68 \\
\hline
\end{tabular}


length (0.39), ankle (-0.31), hind flipper length $(-0.11)$ fore flipper end (0.03) and fore flipper width (0.03) (Fig. 1). PC1 and PC2 explained 72.5 and $15.5 \%$ of the variability in pup morphology measurements respectively. The mean scores between males and females differed by 2.84 for PC 1 (Welch's $t$-test: $t=-38, P=0.05$ ) and 0.18 for PC2 (Welch's $t$-test: $t=-0.22, P=0.84$ ) (Fig. 1).

\section{Trends in isotope values along whiskers}

The $\delta^{15} \mathrm{~N}$ values along the length of pup whiskers did not differ significantly between sexes and were best explained by age: a trough in $\delta^{15} \mathrm{~N}$ values occurred during the transition from gestation to lactation, then $\delta^{15} \mathrm{~N}$ values increased throughout lactation (GAMM; s(Age) $P<0.0001$, $R$-squared $=0.54$; Fig. 2a; Table 2). The individual specialisation index was 0.48 , indicating that individuals used almost half of the sample population's isotopic niche.

The $\delta^{13} \mathrm{C}$ values along the length of whiskers did not differ significantly between sexes and were best explained by age: a trough in $\delta^{13} \mathrm{C}$ values also occurred during the transition from gestation to lactation, but this was less prominent along individual pup whiskers than the trough in $\delta^{15} \mathrm{~N}$ values (GAMM; s(Age) $P<0.0001, R$-squared $=0.27$; Fig. 2b; Table 2). The individual specialisation index was 0.34 . Individuals therefore used a lower proportion of the isotopic niche along the $\delta^{13} \mathrm{C}$ axis than $\delta^{15} \mathrm{~N}$ axis. Two female pups (P2 and P10) had noticeably lower mean $\delta^{13} \mathrm{C}$ values and $\delta^{15} \mathrm{~N}$ values than other pups.

\section{Shifts in isotope values during pup growth}

Pup isotope values shifted among stages of pup growth and there were no significant differences in $\delta^{13} \mathrm{C}$ or $\delta^{15} \mathrm{~N}$

Table 2 Generalised Additive Mixed Model selection with $\delta^{13} \mathrm{C}$ and $\delta^{15} \mathrm{~N}$ values modelled as separate response variables and individual seal modelled as a random effect

\begin{tabular}{lrlcc}
\hline Model terms & d.f & Log-likelihood & AIC & $\Delta$ AIC \\
\hline$\delta^{15}$ N response & & & & \\
s(Age) & 9 & -126.2 & 270.3 & 0 \\
s(Age)+Sex & 10 & -125.8 & 271.6 & 1.3 \\
s(Age + Sex) & 11 & -132.6 & 287.3 & 17 \\
s(Age + Sex)+Sex & 12 & -132.2 & 288.4 & 18.1 \\
Sex & 8 & -208.3 & 432.5 & 162.2 \\
$\delta^{13}$ C response & & & & \\
s(Age) & 9 & -108.4 & 234.9 & 0 \\
s(Age)+Sex & 10 & -108.3 & 236.5 & 1.6 \\
s(Age +Sex) & 11 & -114.6 & 251.2 & 16.3 \\
s(Age + Sex)+Sex & 12 & -114.5 & 253.1 & 18.2 \\
Sex & 8 & -133.2 & 282.3 & 47.4 \\
\hline
\end{tabular}

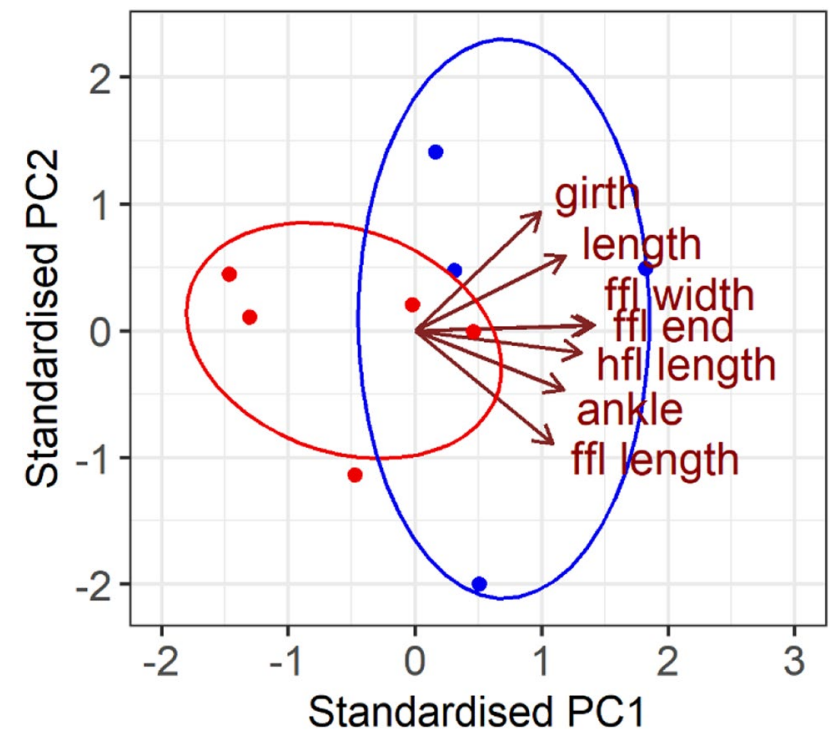

Fig. 1 Relationship between Principal Component 1 (explaining $72.5 \%$ of variability) and Principal Component 2 (explaining 15.5\% of variability) using morphology measurements from 5 female (red) and 4 male (blue) 8 month-old South American fur seal pups ( $f f$ fore flipper; $h f l$ hind flipper)

values between the sexes (Fig. 3; Table 3). The mean $\delta^{13} \mathrm{C}$ value changed from $-15.84 \pm 0.12 \%$ o when the pup was in utero while the mother suckled another pup, to $-15.28 \pm 0.12$ when the pup was in utero and its sibling had weaned, to $-15.59 \pm 0.10$ when the pup suckled from the mother (Linear mixed effects model: $P<0.001$, conditional $R$-squared $=0.31$, marginal $R$-squared $=0.09$ ). The mean $\delta^{15} \mathrm{~N}$ value changed from $15.57 \pm 0.18 \%$ when the pup was in utero while the mother suckled another pup, to $16.32 \pm 0.18 \%$ when the pup was in utero, to

Table 3 Linear Mixed Model selection with $\delta^{13} \mathrm{C}$ and $\delta^{15} \mathrm{~N}$ values modelled as separate response variables and individual seal modelled as a random effect

\begin{tabular}{lcccc}
\hline Model terms & d.f & Log-likelihood & AIC & $\Delta$ AIC \\
\hline$\delta^{15} \mathrm{~N}$ response & & & & \\
$\quad$ Stage & 6 & -196.0 & 404.6 & 0 \\
Sex + Stage & 7 & -195.6 & 405.8 & 1.2 \\
Sex + Stage + Sex $\times$ Stage & 9 & -194.7 & 408.4 & 3.8 \\
Sex & 5 & -208.3 & 426.9 & 22.3 \\
$\delta^{13} \mathrm{C}$ response & & & & \\
Stage & 6 & -113.9 & 240.2 & 0 \\
Sex + Stage & 7 & -113.7 & 242.1 & 1.9 \\
Sex + Stage + Sex $\times$ Stage & 9 & -112.6 & 244.2 & 4.0 \\
Sex & 5 & -133.2 & 276.7 & 36.5 \\
\hline
\end{tabular}

The values for each candidate model include degrees of freedom (d.f.), log-likelihood, AIC value and difference in AIC value ( $\triangle \mathrm{AIC})$ between the candidate model and best-fit model 
Month
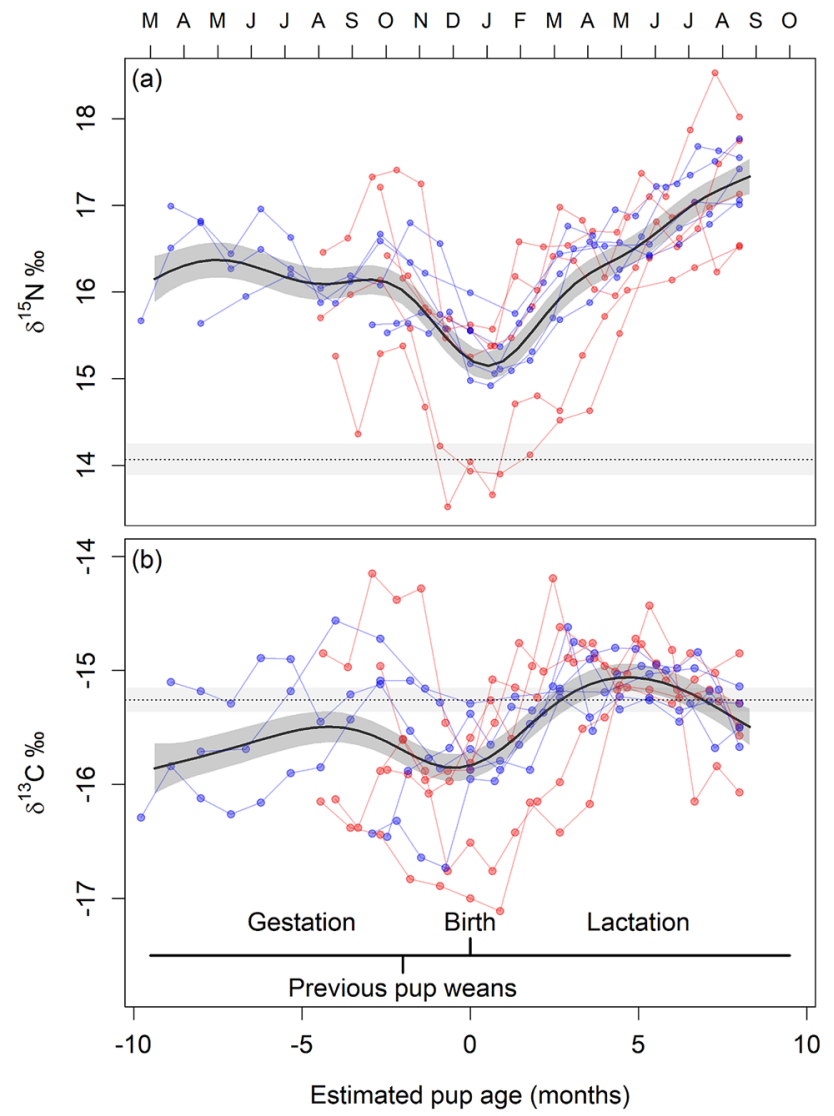

Fig. 2 a $\delta^{13} \mathrm{C}$ values and $\mathbf{b} \delta^{15} \mathrm{~N}$ values along the length of South American fur seal whiskers. Black lines indicate fitted values from Generalised Additive Mixed Models $\left(R\right.$-squared $=0.54$ for $\delta^{15} \mathrm{~N}$ values and 0.27 for $\delta^{13} \mathrm{C}$ values), grey shading represents standard error of fitted values and coloured lines show raw data values along each pup whisker $($ red $=$ females $(n=5)$ and blue $=$ males $(n=5))$. Dotted lines with grey shading show mean isotope value with standard error of distal segments of adult female South American fur seal whiskers grown over the same time period $(n=14)$

$16.17 \pm 0.15 \%$ o when the pup was suckling (Linear mixed effects model: $P<0.001$, conditional $R$-squared $=0.36$, marginal $R$-squared $=0.13$ ) (Table 3). The variance in $\delta^{13} \mathrm{C}$ values significantly differed among stages of pup growth, as variance was greater when mothers were not suckling (due to large differences among individuals) than during other time periods (Levene's test: $F=5.8, P=0.004$ ). However, the variance in $\delta^{15} \mathrm{~N}$ values did not differ significantly among stages of pup growth (Levene's test: $F=2.4$, $P=0.09$ ). Our sample size provided sufficient power for these results, as the repeatability indices of isotope values were significant at $0.11 \pm 0.05$ (CI $0.03-0.23, P<0.001$ ) for $\delta^{13} \mathrm{C}$ and $0.22 \pm 0.12$ (CI $0.06-0.50, P<0.001$ ) for $\delta^{15} \mathrm{~N}$.

\section{Discussion}

This is the first study to quantify trends in stable isotope values along the length of South American fur seal pup whiskers, providing insights into maternal resource use during pup development. We found a characteristic trough in both $\delta^{15} \mathrm{~N}$ and $\delta^{13} \mathrm{C}$ values, which likely occurred around the timing of pup birth, and that $\delta^{15} \mathrm{~N}$ values gradually increased during the lactation period. Isotope values also indicated individual specialisation in resource use by the mothers, particularly along the $\delta^{13} \mathrm{C}$ axis. We explore the underlying drivers of these findings by addressing maternal resource use, as well as physiological processes occurring in mothers and pups, during gestation and lactation.

\section{Gestation}

Trophic enrichment of ${ }^{15} \mathrm{~N}$ was apparent in pup whiskers in utero, as $\delta^{15} \mathrm{~N}$ values were higher than the mean $\delta^{15} \mathrm{~N}$ value in whiskers of adult females breeding at Bird Island (Fig. 2a). Isotopic fractionation in $\delta^{15} \mathrm{~N}$ between mother and offspring during gestation has been found in several marine mammal species, including northern elephant seals and harbour porpoises, Phocoena phocoena (Habran et al. 2010; Fontaine 2002). Small isotope fractionations may occur from placental uptake and excretion between mother and offspring in utero (Fuller et al. 2004). However, the degree of fractionation may change according to maternal foraging success and body condition during pregnancy (Lübcker et al. 2020).

A characteristic trough in $\delta^{15} \mathrm{~N}$ values occurred along pup whiskers (Fig. 2a), which presumably corresponded to timing around pup birth as documented in Steller sea lion pup whiskers (Rea et al. 2015). This pattern may occur in other otariid species, but is often missed as fewer samples are cut from each pup whisker (e.g. Urquía and Páez-Rosas 2019; Baylis et al. 2016). The decline in $\delta^{15} \mathrm{~N}$ values prior to birth may result from maternal changes in prey selection or physiological processes when the pup is still in utero. In some marine mammals, such as bottlenose dolphins, Tursiops truncatus, pregnancy poses an energetic cost by increasing drag forces during swimming (Noren et al. 2011). Pregnancy could also limit dive capacity, for example, dive duration in northern elephant seals declines during the last weeks of pregnancy, potentially because of increased foetal $\mathrm{O}_{2}$ demand (Hückstädt et al. 2018). Females may therefore consume lower trophic level prey that is easier to capture or in higher abundance to meet their physiological abilities and energetic requirements. A change in maternal foraging behaviour is also supported by the corresponding decline in $\delta^{13} \mathrm{C}$ values prior to pup 
Fig. 3 Means (points) and standard deviations (lines) of South American fur seal pup whisker stable isotope values during stages of pup growth: a pup growing in utero while mother suckles an older sibling; b pup growing in utero after sibling has weaned; c pup suckling from mother

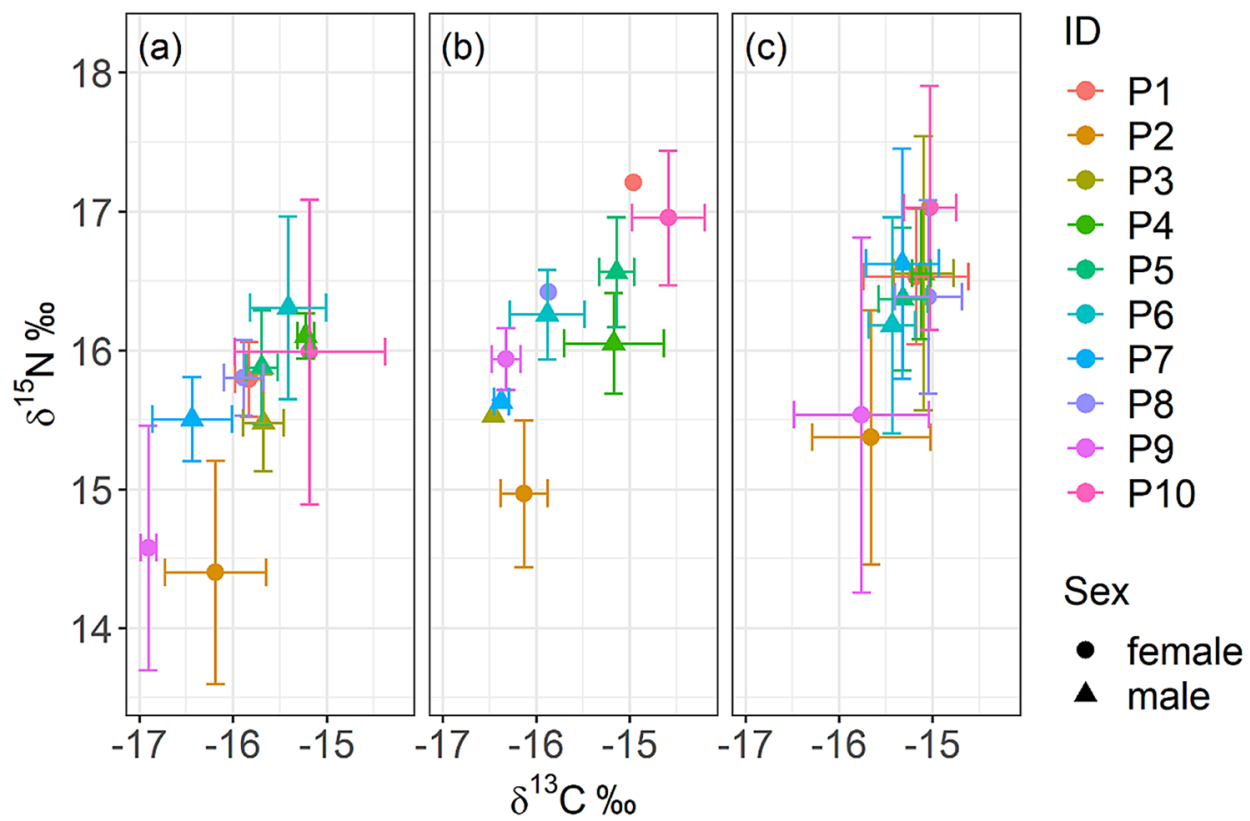

birth. Adult females are free from central place foraging constraints at this time, so have the option of foraging further offshore where baseline $\delta^{13} \mathrm{C}$ values and $\delta^{15} \mathrm{~N}$ values tend to be lower. Indeed, tracking data suggest that some individuals move further offshore on extended foraging trips (Thompson et al. 2003; Baylis et al 2018a).

Alternatively, physiological mechanisms may have driven the decline in $\delta^{15} \mathrm{~N}$ values prior to pup birth. During pregnancy nitrogen stress could activate a complex physiological process, whereby urea synthesis and excretion decrease, while nitrogen is retained and returned to the maternal metabolic pool (Forrester et al. 1994; McClelland et al. 1997; King 2000; Fuller et al. 2004). This may cause a decline in $\delta^{15} \mathrm{~N}$ values in maternal tissues and offspring tissues, which is observed in the fingernails of human mothers and their newborn children (Fuller et al. 2006). The decline in $\delta^{15} \mathrm{~N}$ values may result from more direct routing of amino acids from the diet towards tissues synthesis and/or increased urea salvage in the colon (whereby $\delta^{15} \mathrm{~N}$ values in the diet and urine are lower than the consumer's tissues) (Fuller et al. 2004). This process may occur in otariids, including towards the end of South American fur seal gestation, when pup growth and maintenance place greater demands on the mother. Given that the trend in $\delta^{15} \mathrm{~N}$ values is apparent in humans, Steller sea lion pups and South American fur pups, nitrogen retention may be a common mechanism acting in income breeders prior to giving birth. However, since nitrogen retention alone does not explain the decline in $\delta^{13} \mathrm{C}$ values, we postulate that both nitrogen retention and changes in maternal foraging ecology may explain the decline in stable isotope values prior to pup birth.

\section{Lactation}

During the lactation period adult female otariids are limited in the duration and distance of their foraging trips, so they likely exploit a lower variety of habitats than when they are not suckling a pup (Páez-Rosas and Aurioles-Gamboa 2010; Urquía and Páez-Rosas 2019). Indeed, adult female South American fur seals tracked from Bird Island in 1999 made shorter trips during lactation than when they were freed from central place foraging constraints in spring (Oct-Dec) (Thompson et al. 2003). The $\delta^{13} \mathrm{C}$ values along pup whiskers were therefore more consistent when mothers were suckling pups, as mothers were obliged to forage closer to the colony since time constraints prevented them from accessing habitats further afield. This pattern has also been documented in Galapagos sea lion pup whiskers, Zalophus wollebaeki (Urquía and Páez-Rosas 2019) and may be present in other otariid species.

Variation in adult female habitat use, as indicated by the near-cyclic pattern in $\delta^{13} \mathrm{C}$ values, likely reflects seasonal changes in maternal foraging behaviour, according to the availability and distribution of preferred prey and changing pup needs. In early lactation (mid Dec-Feb), pups are small and could benefit from regular meals (Thompson et al. 2003). Lactating females therefore concentrate their foraging efforts near to Bird Island (Thompson et al. 2003), which is reflected by an increase in $\delta^{13} \mathrm{C}$ values after pup birth. At this time, adult females potentially feed on lobster krill, Munida sp. (a near-shore species), which is a common prey species in the diet of South American fur seals (Strange 1992; Thompson and Moss 2001) that aggregates in dense shoals in January-March (Baylis et al. 2014). In 
April-May, the peak in $\delta^{13} \mathrm{C}$ values and similarity in $\delta^{13} \mathrm{C}$ values among individuals may indicate an influx of prey, driving females to forage in particular regions with higher baseline isotope signatures. For example, Patagonian squid, Doryteuthis gahi, is one of the more frequently occurring prey species in the South American fur seal diet (with that of Falkland herring, Sprattus fuegensis; Baylis et al. 2014), and was particularly abundant in April 2018 (Falkland Islands Government 2019). As the lactation period progresses (mid-May-August), pups can withstand longer fasts and the decline in $\delta^{13} \mathrm{C}$ values indicates that mothers forage further offshore, where they may maximise energy intake. Determining more precise foraging locations from isotopes is difficult, due to complex physical structures and oceanography in this region, such as shelf breaks (where baseline $\delta^{13} \mathrm{C}$ values could be lower than offshore areas from upwelled $\delta^{13} \mathrm{C}$-depleted dissolved inorganic carbon (e.g. Troina et al. 2020)), coupled with incursions of the Falklands current. However, our results indicate that maternal foraging ecology changes throughout reproduction, enabling sufficient allocation of resources to pup growth and development.

The $\delta^{15} \mathrm{~N}$ values along every pup whisker increased as pups aged from 0 to 8 months. This pattern also occurred along Steller sea lion pup whiskers (although $\delta^{15} \mathrm{~N}$ values levelled off around mid-lactation) (Rea et al. 2015) and along fingernails of children (Fuller et al. 2006). It is unlikely that mothers consumed higher trophic level prey, as there was no concurrent increase in $\delta^{15} \mathrm{~N}$ values along adult female whiskers (Baylis et al. unpublished data). Physiological processes in pups had likely overridden the maternal $\delta^{15} \mathrm{~N}$ signatures. During lactation, mothers catabolise their own tissues to synthesise milk and pups start digesting and incorporating nutrients from milk, therefore feeding at a higher trophic level than their mothers (Newsome et al. 2010). Indeed, the tissues of suckling northern fur seal pups, Callorhinus ursinus, and California sea lion pups, Zalophus californianus, were ${ }^{15} \mathrm{~N}$-enriched by $\sim 3 \%$ relative to their mothers (Newsome et al. 2006). Changes in diet are not instantaneously reflected by isotope values, as a result of tissue turnover and the use of amino acids from dietary components as well as endogenous protein reserves (Ayliffe et al. 2004).

Pup fasting cycles likely also contributed to the increasing $\delta^{15} \mathrm{~N}$ values along whiskers. As the lactation period progressed, pups can withstand longer fasts as their mothers undertake longer foraging trips (female trip duration lasts $\sim 100 \mathrm{~h}, \sim 170 \mathrm{~h}$ and $190 \mathrm{~h}$ for those breeding at Bird Island, North Fur Island and Volunteer Rocks, respectively; Thompson et al. 2003; Baylis et al. 2018a). During the austral winter in 2018, adult females breeding at Bird Island had exceptionally long foraging trips and spent up to 3 weeks at sea when pups were approximately 8 months old (Baylis et al. unpublished data). During this time pups fasted ashore and mainly relied on their own energy stores. When animals are under nutritional or physiological stress, they effectively 'feed on themselves' (Cherel et al. 2005). If nitrogen from lean tissues (which is ${ }^{15} \mathrm{~N}$ enriched relative to diet) is used for protein synthesis, then $\delta^{15} \mathrm{~N}$ is preferentially returned to the nitrogen pool and recycled again, resulting in tissues enriched in ${ }^{15} \mathrm{~N}$ (Kurle and Worthy 2001; Fuller et al. 2005; Habran et al. 2010; Newsome et al. 2010). Indeed, this catabolism occurs in Steller sea lion pups after only 2.5 days of fasting (Rea et al. 2000). We therefore propose that South American fur seal pups were in a catabolic-anabolic state during lactation, as their sources of nutrition alternated between milk and their own endogenous stores.

\section{Individual specialisation}

Individual offspring may allocate resources differently because of their sex, size, and condition (Arnould et al. 1996; McDonald et al. 2012a, b). Male South American fur seal pups were slightly larger in body size than females, potentially reflecting the importance of a large body size to future male reproductive success in otariids (Cappozzo et al. 1991). However, whisker length, whisker growth rate, and stable isotope values along whiskers did not significantly differ between male and female pups, indicating that similar resources were allocated into growing these vital sensory organs at this early life stage. For 3 male pups a greater proportion of whisker was present representing in-utero growth, presumably because less abrasion of whisker tips occurred as either a result of pup behaviour or due to more resilient whiskers. Whisker lengths and whisker growth rates may also differ among individual pups as a result of individual differences in maternal investment (Rea et al. 2015).

Stable isotopes in offspring tissues can provide insights into maternal individual specialisation (e.g. Lowther and Goldsworthy 2011). The $\delta^{13} \mathrm{C}$ values along South American fur seal pup whiskers indicated that mothers used less than half the proportion (34\%) of the population's niche along the $\delta^{13} \mathrm{C}$ axis. For example, pups P2 and P9 had notably lower $\delta^{13} \mathrm{C}$ and $\delta^{15} \mathrm{~N}$ values than other pups, suggesting their mothers foraged further offshore and consumed lower trophic level prey than other mothers, representing an alternative foraging strategy. Both $\delta^{13} \mathrm{C}$ and $\delta^{15} \mathrm{~N}$ values were more variable among individuals during early lactation when central place foraging constraints were greater, than during mid-late lactation when these constraints were more relaxed (Fig. 2). During early lactation, mothers' foraging distributions may overlap spatially and competition may force them to specialise (e.g. on benthic vs pelagic prey or different trophic level prey) to enhance their foraging success. Other marine species, such as Gentoo penguins, Pygoscelis papua, also show higher individual specialisation when foraging effort and competition increase (e.g. Ratcliffe et al. 2018). Individual 
specialisation in South American fur seals potentially developed from intense competition, as a result of their colonial breeding and central place foraging, as well as their prolonged lactation period (e.g. Urquía and PáezRosas 2019).

\section{Conclusion}

Stable isotopes in offspring tissues can improve understanding of maternal foraging ecology and physiology. We found that sampling offspring was a valuable method, because offspring could be handled more easily than adults and stable isotopes in their tissues revealed distinct trends during reproduction (e.g. during birth and lactation) and over a relatively long time scale (i.e. over a year). Stable isotope values along otariid pup whiskers can provide broad-scale information on their mother's habitat use, whether foraging habitat or prey changes over time, and whether individual specialisation is present. South American fur seal mothers changed their foraging strategies throughout offspring development, as a result of their changing energetic needs, changes in the pup's ability to fast, and seasonal changes in prey. Individual foraging specialisation was evident, which may enable mothers to forage successfully to enhance pup growth and survival, as well as their own survival. Since both ecological and physiological processes influence isotope values (e.g. with trophic enrichment and pup fasting cycles during lactation complicating the overall picture), interpreting isotope values requires additional knowledge of the species' diet, ecology, and physiology.

Acknowledgements This project was led by the South Atlantic Environmental Research Institute (SAERI) and British Antarctic Survey (BAS). The authors gratefully acknowledge funding from the National Geographic Society (Early Career Explorers Grant), the NERC Life Sciences Mass Spectrometry Facility and the NERC Great Western Four+ Doctoral Training Partnership. They sincerely thank the Falkland Islands Government Fisheries Department, who provided assistance accessing the Bird Island field site. They also thank Dr Rona McGill for her support while running whisker samples through the Isotope Ratio Mass Spectrometer at the Scottish Universities Environmental Research Centre. They additionally thank Dr Kimberley Bennett, Dr Robbie McDonald and two anonymous reviewers for providing valuable feedback on this manuscript.

Funding This study was funded by the National Geographic Society (Early Career Explorers Grant; WW-260ER-17), the NERC Life Sciences Mass Spectrometry Facility (EK280-03/17) and the NERC Great Western Four + Doctoral Training Partnership (GW4 + DTP, NE/ L002434/1).

Data availability Data are available on reasonable request made to the corresponding author or via the Falkland Islands data portalhttp://datap ortal.saeri.org/. Data are stored through the Falkland Islands IMS-GIS Data Center.

\section{Compliance with ethical standards}

Conflicts of interest The authors declare that they have no conflict of interest.

Ethical approval The procedures in this study were reviewed and approved by the Falkland Islands Government. Pups were handled as quickly and efficiently as possible and no pups were injured during handling procedures.

Open Access This article is licensed under a Creative Commons Attribution 4.0 International License, which permits use, sharing, adaptation, distribution and reproduction in any medium or format, as long as you give appropriate credit to the original author(s) and the source, provide a link to the Creative Commons licence, and indicate if changes were made. The images or other third party material in this article are included in the article's Creative Commons licence, unless indicated otherwise in a credit line to the material. If material is not included in the article's Creative Commons licence and your intended use is not permitted by statutory regulation or exceeds the permitted use, you will need to obtain permission directly from the copyright holder. To view a copy of this licence, visit http://creativecommons.org/licenses/by/4.0/.

\section{References}

Araújo MS, Bolnick DI, Layman CA (2011) The ecological causes of individual specialisation. Ecol Lett 14(9):948-958

Arnould JP, Hindell MA (2002) Milk consumption, body composition and pre-weaning growth rates of Australian fur seal (Arctocephalus pusillus doriferus) pups. J Zool 256(3):351-359

Arnould JPY, Boyd IL, Socha DG (1996) Milk consumption and growth efficiency in Antarctic fur seal (Arctocephalus gazella) pups. Can J Zool 74:254-266

Aurioles D, Koch PL, Le Boeuf BJ (2006) Differences in foraging location of Mexican and California elephant seals: evidence from stable isotopes in pups. Mar Mamm Sci 22(2):326-338

Ayliffe LK, Cerling TE, Robinson T, West AG, Sponheimer M, Passey BH, Hammer J, Roeder B, Dearing MD, Ehleringer JR (2004) Turnover of carbon isotopes in tail hair and breath $\mathrm{CO} 2$ of horses fed an isotopically varied diet. Oecologia 139:11-22

Baylis AMM, Page B, Goldsworthy SD (2008) Effect of seasonal changes in upwelling activity on the foraging locations of a wideranging central-place forager, the New Zealand fur seal. Can J Zool 86(8):774-789

Baylis AMM, Arnould JP, Staniland IJ (2014) Diet of South American fur seals at the Falkland Islands. Mar Mamm Sci 30(3):1210-1219

Baylis AMM, Kowalski GJ, Voigt CC, Orben RA, Trillmich F, Staniland IJ, Hoffman JI (2016) Pup vibrissae stable isotopes reveal geographic differences in adult female southern sea lion habitat use during gestation. PLoS ONE 11(6):e0157394

Baylis AMM, Tierney M, Orben RA, Staniland IJ, Brickle P (2018a) Geographic variation in the foraging behaviour of South American fur seals. Mar Ecol Prog Ser 596:233-245

Baylis AMM, Tierney M, Staniland IJ, Brickle P (2018b) Habitat use of adult male South American fur seals and a preliminary assessment of spatial overlap with trawl fisheries in the South Atlantic. Mamm Biol 93:76-81

Baylis AMM, Orben RA, Arkhipkin AA, Barton J, Brownell RL Jr, Staniland IJ, Brickle P (2019) Re-evaluating the population size of South American fur seals and conservation implications. Aquatic Conserv: Mar Freshw Ecosyst 29(11):1988-1995 
Ben-David M, Flaherty EA (2012) Stable isotopes in mammalian research: a beginner's guide. J Mamm 93(2):312-328

Berger J (1991) Pregnancy incentives, predation constraints and habitat shifts: experimental and field evidence for wild bighorn sheep. Anim Behav 41:61-77

Bolnick DI, Yang LH, Fordyce JA, Davis JM, Svanbäck R (2002) Measuring individual-level resource specialization. Ecology 83(10):2936-2941

Bowman DM, Murphy BP, McMahon CR (2010) Using carbon isotope analysis of the diet of two introduced Australian megaherbivores to understand Pleistocene megafaunal extinctions. J Biogeogr 37(3):499-505

Cappozzo HL, Campagna C, Monserrat J (1991) Sexual dimorphism in newborn southern sea lions. Marine Mammal Science 7(4):385-394

Cherel Y, Hobson KA, Bailleul F, Groscolas R (2005) Nutrition, physiology, and stable isotopes: new information from fasting and molting penguins. Ecology 86(11):2881-2888

Cherel Y, Kernaléguen L, Richard P, Guinet C (2009) Whisker isotopic signature depicts migration patterns and multi-year intraand inter-individual foraging strategies in fur seals. Biol Let 5(6):830-832

Coplen TB, Brand WA, Gehre M, Gröning M, Meijer HA, Toman B, Verkouteren RM (2006) New guidelines for $\delta$ 13C measurements. Anal Chem 78(7):2439-2441

R Core Team (2019) R: A language and environment for statistical computing. R Foundation for Statistical Computing, Vienna, Austria. https://www.r-project.org/ Accessed 15 Nov 2019.

Crocker LM, DePeters EJ, Fadel JG, Perez-Monti H, Taylor SJ, Wyckoff JA, Zinn RA (1998) Influence of processed corn grain in diets of dairy cows on digestion of nutrients and milk composition. J Dairy Sci 81(9):2394-2407

DeNiro MJ, Epstein S (1976) You are what you eat (plus a few \%o). Geol Soc Am 8:834-835

Drago M, Cardona L, Crespo EA, García N, Ameghino S, Aguilar A (2010) Change in the foraging strategy of female South American sea lions (Carnivora: Pinnipedia) after parturition. Scientia Marina 74(3):589-598

Estes JA, Riedman ML, Staedler MM, Tinker MT, Lyon BE (2003) Individual variation in prey selection by sea otters: patterns, causes and implications. J Anim Ecol 72:144-155

Estes JA, Heithaus M, McCauley DJ, Rasher DB, Worm B (2016) Megafaunal impacts on structure and function of ocean ecosystems. Ann Rev Environ Res 41:83-116

Falkland Islands Government (2019) Fisheries Department Fisheries Statistics, Volume 23, 2018: 102pp Stanley, FIG Fisheries Department.

Fontaine M (2002) Sources de variation des concentrations en métaux traces du marsouin commun (Phocoena phocoena) (L.) capturés dans des filets le long des côtes norvégiennes. M.S. dissertation, Université de Liège, Liège, Belgium.

Forrester T, Badaloo AV, Persaud C, Jackson AA (1994) Urea production and salvage during pregnancy in normal Jamaican women. Am J Clin Nutr 60(3):341-346

France RL (1995) Differentiation between littoral and pelagic food webs in lakes using stable carbon isotopes. Limnol Oceanogr 40(7):1310-1313

Franco-Trecu VF (2005) Comportamiento maternal y aspectos reproductivos de Arctocephalus australis en Isla de Lobos, Uruguay. Doctoral dissertation, Tesis de Grado. Facultad de Ciencias, Universidad de la República, Montevideo, Uruguay.

Fry B (1988) Food web structure on Georges Bank from stable C, N, and $\mathrm{S}$ isotopic compositions. Limnol Oceanogr 33(5):1182-1190

Fuller BT, Fuller JL, Sage NE, Harris DA, O'Connell TC, Hedges RE (2004) Nitrogen balance and $\delta 15 \mathrm{~N}$ : Why you're not what you eat during pregnancy. Rapid Commun Mass Spectrom 18(23):2889-2896

Fuller BT, Fuller JL, Sage NE, Harris DA, O'Connell TC, Hedges RE (2005) Nitrogen balance and $\delta 15 \mathrm{~N}$ : why you're not what you eat during nutritional stress. Rapid Commun Mass Spectrom 19(18):2497-2506

Fuller BT, Fuller JL, Harris DA, Hedges RE (2006) Detection of breastfeeding and weaning in modern human infants with carbon and nitrogen stable isotope ratios. Am J Phys Anthropol 129(2):279-293

Gittleman JL, Thompson SD (1988) Energy allocation in mammalian reproduction. Am Zool 28(3):863-875

Habran S, Debier C, Crocker DE, Houser DS, Lepoint G, Bouquegneau JM, Das K (2010) Assessment of gestation, lactation and fasting on stable isotope ratios in northern elephant seals (Mirounga angustirostris). Mar Mamm Sci 26(4):880-895

Hindell MA, Lydersen C, Hop H, Kovacs KM (2012) Pre-partum diet of adult female bearded seals in years of contrasting ice conditions. PLoS ONE 7(5):e38307. https://doi.org/10.1371/journ al.pone.0038307

Hobson KA, Piatt JF, Pitocchelli J (1994) Using stable isotopes to determine seabird trophic relationships. J Anim Ecol 63:786-798

Hückstädt LA, Holser RR, Tift MS, Costa DP (2018) The extra burden of motherhood: reduced dive duration associated with pregnancy status in a deep-diving mammal, the northern elephant seal. Biol Let 14(2):20170722

Jackson AL, Parnell AC, Inger R, Bearhop S (2011) Comparing isotopic niche widths among and within communities: SIBER-Stable Isotope Bayesian Ellipses in R. J Anim Ecol 80(3):595-602

Jeglinski J, Werner C, Robinson P, Costa D, Trillmich F (2012) Age, body mass and environmental variation shape the foraging ontogeny of Galapagos sea lions. Mar Ecol Prog Ser 453:279-296

Jenkins SG, Partridge ST, Stephenson TR, Farley SD, Robbins CT (2001) Nitrogen and carbon isotope fractionation between mothers, neonates, and nursing offspring. Oecologia 129(3):336-341

Jones KA, Wood H, Ashburner JP, Forcada J, Ratcliffe N, Votier SC, Staniland IJ (2020a) Risk exposure trade-offs in the ontogeny of sexual segregation in Antarctic fur seal pups. Behav Ecol 31:719-730

Jones KA, Ratcliffe N, Votier SC, Newton J, Forcada J, Dickens J, Stowasser G, Staniland IJ (2020b) Intra-specific niche partitioning in Antarctic fur seals Arctocephalus gazella. Sci Rep 10(1):3238

Kelly JF (2000) Stable isotopes of carbon and nitrogen in the study of avian and mammalian trophic ecology. Can J Zool 78:1-27

Kernaléguen L, Cherel Y, Knox TC, Baylis AM, Arnould JP (2015) Sexual niche segregation and gender-specific individual specialisation in a highly dimorphic marine mammal. PLoS ONE 10(8): $\mathrm{e} 0133018$

King JC (1225S) Physiology of pregnancy and nutrient metabolism. Am J Clin Nutr 71(5):1218S-1225S

Krebs JR, Davies NB (1997) Behavioural ecology: an evolutionary approach, 4th edn. Black-well Publishing, Oxford, UK, p 464

Kurle CM, Worthy GA (2001) Stable isotope assessment of temporal and geographic differences in feeding ecology of northern fur seals (Callorhinus ursinus) and their prey. Oecologia 126(2):254-265

Laidre KL, Stirling I, Lowry LF, Wiig Ø, Heide-Jørgensen MP, Ferguson SH (2008) Quantifying the sensitivity of arctic marine mammals to climate-induced habitat change. Ecol Appl 18:S97-S125

Laptikhovsky V (2009) Oceanographic factors influencing the distribution of South American fur seal, Arctocephalus australis around the Falkland Islands before the breeding season. J Mar Biol Assoc UK 89(8):1597-1600

Lima M, Páez E (1995) Growth and reproductive patterns in the South American fur seal. J Mamm 76(4):1249-1255 
Lowther AD, Goldsworthy SD (2011) Detecting alternate foraging ecotypes in Australian sea lion (Neophoca cinerea) colonies using stable isotope analysis. Mar Mamm Sci 27(3):567-586

Lübcker N, Whiteman JP, Newsome SD, Millar RP, de Bruyn PN (2020) Can the carbon and nitrogen isotope values of offspring be used as a proxy for their mother's diet Using foetal physiology to interpret bulk tissue and amino acid $\delta 15 \mathrm{~N}$ values. Conserv Physiol 8(1):060

McClelland IS, Persaud C, Jackson AA (1997) Urea kinetics in healthy women during normal pregnancy. Br J Nutr 77(2):165-181

McCutchan JH, Lewis WM, Kendall C, McGrath CC (2003) Variation in trophic shift for stable isotope ratios of carbon, nitrogen, and sulfur. Oikos 102:378-390

McDonald BI, Goebel ME, Crocker DE, Costa DP (2012a) Dynamic influence of maternal and pup traits on maternal care during lactation in an income breeder, the Antarctic fur seal. Physiol Biochem Zool 85(3):243-254. https://doi.org/10.1086/665407

McDonald BI, Goebel ME, Crocker DE, Costa DP (2012b) Biological and environmental drivers of energy allocation in a dependent mammal, the Antarctic fur seal pup. Physiol Biochem Zool 85(2):134-147. https://doi.org/10.1086/664948

McHuron EA, Holser RR, Costa DP (2019) What's in a whisker? Disentangling ecological and physiological isotopic signals. Rapid Commun Mass Spectrom 33(1):57-66

Meissner AM, MacLeod CD, Richard P, Ridoux V, Pierce G (2012) Feeding ecology of striped dolphins, Stenella coeruleoalba, in the north-western Mediterranean Sea based on stable isotope analyses. J Mar Biol Ass UK 92(8):1677-1687

Minagawa M, Wada E (1984) Stepwise enrichment of $15 \mathrm{~N}$ along food chains: further evidence and the relation between $\delta 15 \mathrm{~N}$ and animal age. Geochim Cosmochim Acta 48(5):1135-1140

Nakagawa S, Schielzeth H (2010) Repeatability for Gaussian and non-Gaussian data: a practical guide for biologists. Biol Rev 85:935-956

Newsome SD, Koch PL, Etnier MA, Aurioles-Gamboa D (2006) Using carbon and nitrogen isotope values to investigate maternal strategies in northeast Pacific otariids. Mar Mamm Sci 22(3):556-572

Newsome SD, Clementz MT, Koch PL (2010) Using stable isotope biogeochemistry to study marine mammal ecology. Mar Mamm Sci 26(3):509-572

Noren SR, Redfern JV, Edwards EF (2011) Pregnancy is a drag: hydrodynamics, kinematics and performance in pre- and postparturition bottlenose dolphins (Tursiops truncatus). J Exp Biol 214:4151-4159

Olin JA, Hussey NE, Fritts M, Heupel MR, Simpfendorfer CA, Poulakis GR, Fisk AT (2011) Maternal meddling in neonatal sharks: implications for interpreting stable isotopes in young animals. Rapid Commun Mass Spectrom 25(8):1008-1016

Páez-Rosas D, Aurioles-Gamboa D (2010) Alimentary niche partitioning in the Galapagos sea lion Zalophus wollebaeki. Mar Biol 157(12):2769-2781

Pinheiro J, Bates D, DebRoy S, Sarkar D, R Core Team (2019) nlme: Linear and Nonlinear Mixed Effects Models. https://CRAN.Rproject.org/package=nlme/ Accessed 15 Nov 2019.

Polischuk SC, Hobson KA, Ramsay MA (2001) Use of stable-carbon and-nitrogen isotopes to assess weaning and fasting in female polar bears and their cubs. Can J Zool 79(3):499-511

Post DM (2002) Using stable isotopes to estimate trophic position: models, methods, and assumptions. Ecology 83(3):703-718

Qi H, Coplen TB, Geilmann H, Brand WA, Böhlke JK (2003) Two new organic reference materials for $\delta 13 \mathrm{C}$ and $\delta 15 \mathrm{~N}$ measurements and a new value for the $\delta 13 \mathrm{C}$ of NBS 22 oil. Rapid Commun Mass Spectrom 17(22):2483-2487

Rachlow JL, Bowyer RT (1998) Habitat selection by Dall's sheep (Ovis dalli): maternal trade-offs. J Zool 245:457-465
Ratcliffe N, Adlard S, Stowasser G, McGill R (2018) Dietary divergence is associated with increased intra-specific competition in a marine predator. Sci Rep 8(1):1-10

Rea LD, Rosen DA, Trites AW (2000) Metabolic response to fasting in 6-week-old Steller sea lion pups (Eumetopias jubatus). Can J Zool 78(5):890-894

Rea LD, Christ AM, Hayden AB, Stegall VK, Farley SD, Stricker CA, Mellish JAE, Maniscalco JM, Waite JN, Burkanov VN, Pitcher KW (2015) Age-specific vibrissae growth rates: a tool for determining the timing of ecologically important events in Steller sea lions. Marine Mamm Sci 31(3):1213-1233

Roughgarden J (1972) Evolution of niche width. Am Nat 106:683-718

Spurlin SM, Peterson SH, Crocker DE, Costa DP (2019) Nitrogen and carbon stable-isotope ratios change in adult northern elephant seals (Mirounga angustirostris) during the breeding and molting fasts. Marine Mamm Sci 35(2):707-717

Stoffel MA, Nakagawa S, Schielzeth H (2019) An introduction to repeatability estimation with rptR. https://cran.r-project.org/web/ packages/rptR/vignettes/rptR.html Accessed 07 March 2020.

Strange IJ (1992) A field guide to the wildlife of the Falkland Islands and South Georgia. Harper Collins, London

Thompson D, Moss S (2001) Foraging behaviour of South American fur seals (Arctocephalus australis) in the Falkland Islands. Unpublished Sea Mammal Research Unit Report to Falklands Conservation.

Thompson D, Moss SE, Lovell P (2003) Foraging behaviour of South American fur seals Arctocephalus australis: extracting fine scale foraging behaviour from satellite tracks. Mar Ecol Prog Ser 260:285-296

Troina GC, Dehairs F, Botta S, Di Tullio JC, Elskens M, Secchi ER (2020) Zooplankton-based $\delta^{13} \mathrm{C}$ and $\delta^{15} \mathrm{~N}$ isoscapes from the outer continental shelf and slope in the subtropical western South Atlantic. Deep Sea Res Part I 159:103235

Urquía DO, Páez-Rosas D (2019) $\delta 13 \mathrm{C}$ and $\delta 15 \mathrm{~N}$ values in pup whiskers as a proxy for the trophic behavior of Galapagos sea lion females. Mamm Biol 96(1):28-36

Villegas-Amtmann S, Costa D, Tremblay Y, Salazar S, AuriolesGamboa D (2008) Multiple foraging strategies in a marine apex predator, the Galapagos sea lion Zalophus wollebaeki. Mar Ecol Prog Ser 363:299-309

Villegas-Amtmann S, McDonald BI, Páez-Rosas D, Aurioles-Gamboa D, Costa DP (2017) Adapted to change: low energy requirements in a low and unpredictable productivity environment, the case of the Galapagos sea lion. Deep Sea Res Part II 140:94-104

Wolf JB, Harrod C, Brunner S, Salazar S, Trillmich F, Tautz D (2008) Tracing early stages of species differentiation: ecological, morphological and genetic divergence of Galápagos sea lion populations. BMC Evol Biol 8(1):150

Wood SN (2017) Mgcv. Mixed GAM Computation Vehicle with GCV/ AIC/REML Smoothness Estimation. https://stat.ethz.ch/R-manua 1/R-devel/library/mgcv/html/mgcv-package.html Accessed 15 Nov 2019.

Zango L, Reyes-González JM, Militão T, Zajková Z, Álvarez-Alonso E, Ramos R, González-Solís J (2019) Year-round individual specialization in the feeding ecology of a long-lived seabird. Sci Rep 9(1):1-12

Publisher's Note Springer Nature remains neutral with regard to jurisdictional claims in published maps and institutional affiliations. 